American Journal of Applied Sciences 8 (9): 864-871, 2011

ISSN 1546-9239

(C) 2011 Science Publications

\title{
Developing the Environment of Information Technology Education using Cloud Computing Infrastructure
}

\author{
${ }^{1}$ Chen-Feng Wu and ${ }^{1,2}$ Liang-Pang Huang \\ ${ }^{1}$ Department of Information Management, Yu Da University, Taiwan \\ ${ }^{2}$ Wen Feng Elementary School, Miaoli County, Taiwan
}

\begin{abstract}
The education of Information Technology (IT) in Taiwan has been promoted since 1997. However, there were still problems with the current environment of IT education. Problem statement: The major problem was that students were unable to practice after school with the same environment and there was no appropriate space to save their files for students, so it was not convenient for students' achievement of learning. Approach: The service of private cloud computing was adopted in this study to establish the education environment of information technology for resolving these problems. The browser was used to link the cloud computing service that provided web operating system, application program and file manager and the purpose was to increase the learning efficiency and convenience. Results: The quasi-experimental method was applied to the study of 110 fifth grade students who were selected from Tunglo Elementary School in Miaoli County, Taiwan. Conclusion: The experiment results showed that students' learning achievement with the environment of IT educational of cloud computing was better than the ones with traditional IT educational environment. Therefore, the cloud computing infrastructure was recommended to construct the environment of IT education in real world.
\end{abstract}

Key words: Information technology, cloud computing service, technology acceptance model, operating system, application program, recovery system, interactive collaboration

\section{INTRODUCTION}

Backgrounds of research: It was the focus of every nation's education development to let every citizen has the knowledge and the ability of using information technology in the information oriented society. Thus, the projects of IT education were promoted to lay the development foundation for the nations in the twentyfirst century.

The introduction of Information Technology (IT) to government institutions in developing countries bears a great deal of risk of failure. The lack of qualified personnel, lack of financial support and the lack of planning and proper justification are just few of the causes of projects failure (Issa et al., 2009).

New Zealand started IT education for elementary and secondary schools in 1990. The project, Professional Development Cluster which promoted at 1999, was to let the seed schools of IT to help neighboring schools for the development of IT education. The plan called Kaupapa Ara Whakawhiti Matauranga (KAWM) and released in 2001 was to help Maori schools which located at underdeveloped areas to reduce the information gap. The lease project of teachers' notebook computer for junior high schools was released to enhance the teachers' ability of IT teaching between the year 2002 and 2003 (Hsieh, 2008). A study attempts to review on challenges and infrastructure of e-learning in developing countries specially Iran (Omidinia et al., 2011).

Taiwan's Ministry of Education released the infrastructure project of IT education in 1997 and the project content consists of subsidizing the elementary and junior high schools for building computer classrooms, purchasing software and constructing campus network. The IT education of elementary and junior high schools was formally incorporated into the curriculum since 2001 and the Curriculum was begun from Grade 1-9 (Zhong et al., 2009). IT education of schools was mainly conducted in computer classroom. The maintaining of dozens of computers in the computer classroom becomes a burden for the manager. The literature had discussed the way of improving management of computer classroom, for example: computer lab management using free software (Belkasmi et al., 2010). Implementation of a diskless cluster computing environment in a computer classroom (Hsieh, 2008) and the development of teaching network management system in computer classroom. The structures of computer classrooms 
discussed in these literatures were closed systems and students could not connect to them for operation from outside of school. The research about the effectiveness of computer usage frequency for students in the learning achievement of computer had found that more frequent use of computer leads to a better computer learning achievement. Thus, if students could continue practice IT lessons taught at school when they were after school, it will be a great benefit to the learning achievement.

The main purpose of using freeware for teaching was to let students easily obtain software. Students had to download and install the software before using and the installation procedures of software were difficult for elementary school students. Besides, there is still another problem which is lacking of proper space for students to save files during class always bothering the teachers of IT education. The files are usually saved at local disk of computer classroom, but the computer classroom is shared with all students. Thus, the files could be altered or deleted by other user. Besides, the research results in Taiwan Commission of Research Development and Evaluation indicated that software obtainments were troubled for the students. This causes inconvenience for the students' learning.

Purpose of research: Students' learning is no longer confined within the classroom in the era of e-learning 2.0. The environment of IT education could be improved to let student access learning resources anywhere. The free software is adopted for constructing the private cloud computing service for the environment of IT education to address the above shortcomings in this study and to improve the environment of IT education for elementary and junior high schools and provided students with various education services of information technology, such as word processing, spreadsheets, presentations. Only a browser is needed for students to connect to the cloud computing service for learning. The purposes of this research were shown as follows:

- To build an environment of IT education based on the infrastructure of cloud computing, students only need the browser to login for learning and managing files anywhere

- To find out the computer learning achievement of elementary students after using the environment of IT education of cloud computing service for learning

Related work: The environment of IT education should be friendly and be used easily for users and they can also have students use it and increase students' learning achievements. Some Researchers have tried to adopt the concept of cloud computing to improve the environment of IT education as the speed of the Internet has been significantly improved and the concept of the cloud computing has risen rapidly. In literature common tasks could be done with a browser and the functions such as course management and interactive collaboration between teacher and student were also provided.

Status of information technology education environment: The computers used for IT education at school were mainly personal computers. In order to get the personal computer to work, the operation systems and the application programs must be installed. However, the compatibility of the application software with the operating system, the installation steps and software updates were difficult for elementary school students to make up the same computer environment as the school. Some researchers think of building the operation system and application program on the cloud so that users do not have to worry about the software installation and program update, but it is impossible to have the current application software to work in the cloud computing operation system. The study of "vSaaS: A Virtual Software as a Service Architecture for Cloud Computing Environment" had provided a solution and the solution is that platforms are built with virtual personal desktop environment and remote display technology (Zhong et al., 2009). Users use the client device to access the cloud operation system just like using the local computer so that the study showed the feasibility and effectiveness for the vSAAS system.

The IT education environment of elementary and junior high schools consist two parts: class IT equipment and computer classroom, as shown in Table 1. The current environment of IT education of elementary and junior high schools consists of two parts: the IT equipment of in normal classroom and the computer classroom. There were interactive whiteboard, personal computer, projector and wireless network access point for the IT equipments of classroom that can provide teachers to incorporate information technology into Teaching. A computer classroom was a main place for training student's information ability and it also could be used for incorporate information technology into teaching. There were two kinds of systems that were used for implementing the computer classroom and they are system with disk and diskless system, respectively. 
Am. J. Applied Sci., 8 (9): 864-871, 2011

Table 1: Current status of environment of it education in elementary and junior schools

\begin{tabular}{|c|c|c|}
\hline Items & Equipments & Usage \\
\hline IT equipment in class & $\begin{array}{l}\text { Interactive whiteboard, personal computer, } \\
\text { projector, wireless network access point }\end{array}$ & $\begin{array}{l}\text { incorporate information technology } \\
\text { into teaching plans }\end{array}$ \\
\hline $\begin{array}{l}\text { Computer System classroom } \\
\text { with disk }\end{array}$ & $\begin{array}{l}\text { Client's computer equipped with hard disk } \\
\text { operation system and application program } \\
\text { Were installed at local disk, a recovery, } \\
\text { system was installed to protect data from } \\
\text { been erased for local host and a broadcast } \\
\text { teaching system was install in teacher's } \\
\text { computer to monitor students learning } \\
\text { situation and broadcast teacher's } \\
\text { Screen for instruction. }\end{array}$ & $\begin{array}{l}\text { 1.incorporate } \\
\text { Information technology } \\
\text { into teaching plans } \\
\text { 2. training of } \\
\text { Information ability }\end{array}$ \\
\hline Diskless system & $\begin{array}{l}\text { Client's computer does not have hard disk, } \\
\text { Operation system and application programs } \\
\text { were installed at diskless server as image } \\
\text { files and student's computer read image } \\
\text { files of servers through intranet to start. } \\
\text { A broadcast teaching system was install in } \\
\text { teacher's computer to monitor students' } \\
\text { learning situation and to broadcast } \\
\text { teacher's screen for instruction }\end{array}$ & $\begin{array}{l}\text { 1.incorporate } \\
\text { information technology } \\
\text { into teaching plans } \\
\text { 2.information } \\
\text { ability training }\end{array}$ \\
\hline
\end{tabular}

Source: Edited by Authors

For disk system, the client's computer is equipped with hard disk, operation system and application program were installed at local disk and recovery system was installed to protect data from been erased. For diskless system, client's computer does not need to install hard disk, operation system and application program were installed at diskless server as image files and student's computer read image files of servers through intranet for starting.

Cloud computing: Cloud services can be provided through the network, but not all of Internet services are the cloud services. The definition of cloud computing based on the National Institute of Standards and Technology is a model for enabling convenient, ondemand network access to a shared pool of configurable computing resources that can be rapidly provisioned and released with minimal management effort or interaction of service provider. For such a cloud model promotes availability and is composed of five essential characteristics, on-demand self-service, access of broadband network, resource pooling, rapid elasticity, measured service. There are three service models of cloud, including Software as a Service (SaaS), Cloud Platform as a Service (PaaS), Cloud Infrastructure as a Service (IaaS) and four deployment models of Private cloud, including Community cloud, Public cloud, Hybrid cloud mentioned in (Mell and Grance, 2009) Generally defined in this manner, some businesses named this kind of applications "cloud services" or "services in the cloud". Gartner, Inc. analysts presented their findings about the top ten technologies and trends that will be strategic for most organizations in 2010
(Gartner, 2010) and the cloud computing was ranked first. Besides, Microsoft, Amazon, IBM and other major IT companies have also invested cloud computing technology and applications. The term of cloud computing gradually has gotten attention since 2007 and this is also the trend for the development of information technology. Besides, there was also similar plan proposed by Taiwan government on April 29th 2010 Taiwan. Through the execution of this plan, Taiwan will be able to apply new cloud computing technology to creating an intelligent, quality lifestyle and to moving toward becoming a major technological power.

There are the three kinds of cloud services, public cloud, hybrid cloud and private cloud, discussed in "2009 Cloud Computing Conference and Expo" which held in California. Many businesses were optimistic about the potential development of private cloud service and the main reason was the consideration of information security and integration within the demanders' system. Advances in virtualization technology will also be a driven force for the growth of private cloud applications. The implementation of private cloud will become easier when the existing system is able to use virtualization technology and effectively constructs and manages more services. Besides, cloud computing service can be regarded as a solution for the technology-based classroom and it can encourage industry development for related services and indirectly leads to market development. Therefore, the private cloud service was adopted to implement the environment of IT education in this study. 
Cloud operation system: Cloud operation system which provides platform as a service is an operation system on the Internet and users can use a browser to access for services. Because the requirements of cloud operation system for this study must be suitable for the environment of IT education, the items of open source freeware, office software, file manager and file upload will be considered. The comparison of current cloud operation system was shown as Table 2.

The cloud operation systems, Cloudo, GlideOS, iCloud and MyGoya, are open platforms, so users may use them after free registration. The system provides office software, such as word processor, spreadsheets, presentation, the function of file manager and file upload. The cloud operation system, Startforce, provides complete office software and file manager function, even though the Microsoft office software could also run under this system. Because the system had to be paid for use EyeOS is the most suitable cloud operation system for this research.

\section{MATERIALS AND METHODS}

The research design, private cloud computing system design, research instrument and data analysis will be described as follows.

Research design: This study aimed to compare the difference between the achievement of computer learning after using the environment of IT education of cloud computing service and the one after using tradition environment of IT education. The quasiexperimental method was adopted to study four classes of 110 fifth grade students from Tunglo Elementary School in Miaoli County, Taiwan. Two classes which have 55 students were selected with non-random sampling as the experimental group and adopted the environment of IT education of cloud computing for learning. The other two classes were control group which also has 55 students and adopted the traditional IT environment for learning. These two groups were taken "pretest of learning achievement" and verified for homogeneity in basic ability before the experiment teaching was conducted. The schedule of experiment teaching had been executed for four weeks, one period a week, 40 minutes a period and the content of lesson is spreadsheet. At the end of four weeks experiment teaching, all participants were taken "posttest of learning achievement" and the data analyses were conducted for the results at the end.
System design of private cloud computing: Private cloud, as shown in Fig. 1, was applied to constructing the environment of IT education in this study and users must have account and password to access the system for control and management. The cloud computing server located inside school can be connected through the Internet, so students can connect to the service for learning even though they are home. The cloud server provides the following services, as shown in Fig. 2: Infrastructure as a Service: server hardware, Platform as a Service: web operation system, Storage as a Service: file manager system and Software as a Service: word processor, spreadsheets, presentation, calendar, internal message. Students connect to the cloud server of which students can login personal space for work via the Internet and students' practice files can be sent to teachers by using the function of internal message.

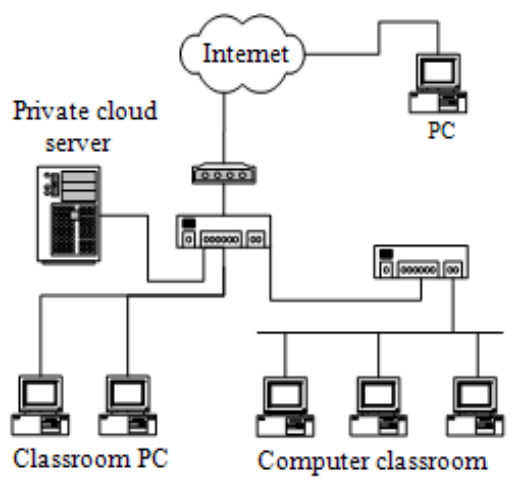

Fig.1:System architecture diagram of Private cloud computing service for the environment of IT education

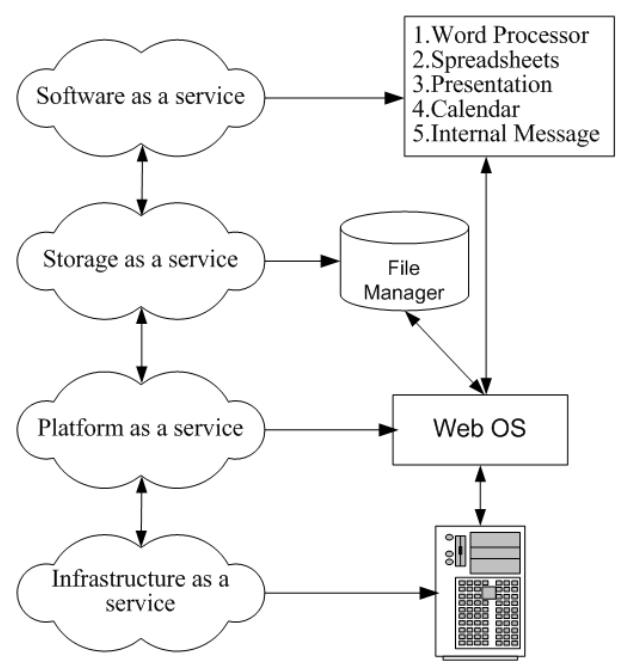

Fig. 2: Structure of cloud computing service 
Am. J. Applied Sci., 8 (9): 864-871, 2011

Table 2: Comparison of current cloud operation system

\begin{tabular}{|c|c|c|c|c|c|c|c|}
\hline \multirow[b]{2}{*}{$\begin{array}{l}\text { Cloud operation } \\
\text { system }\end{array}$} & \multicolumn{4}{|c|}{ Office software } & \multirow[b]{2}{*}{$\begin{array}{l}\text { File } \\
\text { manager }\end{array}$} & \multirow[b]{2}{*}{$\begin{array}{l}\text { File } \\
\text { upload }\end{array}$} & \multirow[b]{2}{*}{ Remark } \\
\hline & $\begin{array}{l}\text { Open } \\
\text { source }\end{array}$ & $\begin{array}{l}\text { Word } \\
\text { processor }\end{array}$ & $\begin{array}{l}\text { Spread } \\
\text { sheets }\end{array}$ & Presentation & & & \\
\hline Cloudo & - & Yes & - & - & Yes & Yes & Open platform \\
\hline eyeOS & Yes & Yes & Yes & Yes & Yes & Yes & \\
\hline GlideOS & No & Yes & Yes & Yes & Yes & Yes & Open platform \\
\hline iCloud & - & Yes & Yes & Yes & Yes & Yes & Open platform \\
\hline MyGoya & - & Yes & Yes & Yes & Yes & Yes & Open platform \\
\hline Startforce & - & Yes & Yes & Yes & Yes & Yes & \\
\hline
\end{tabular}

Source: Edited by Authors

Table 3: Summary of analysis for the pretest questions

\begin{tabular}{lllllllc}
\hline $\begin{array}{l}\text { Question } \\
\text { number }\end{array}$ & Difficulty & Discrimination & Selection & $\begin{array}{l}\text { Question } \\
\text { number }\end{array}$ & Difficulty & Discrimination & Selection \\
\hline 1 & 0.64 & 0.71 & $\checkmark$ & 12 & 0.44 & 0.45 & $\checkmark$ \\
2 & 0.82 & 0.22 & Delete & 13 & 0.18 & -0.22 & Delete \\
3 & 0.54 & 0.51 & $\checkmark$ & 14 & 0.41 & 0.39 & $\checkmark$ \\
4 & 0.51 & 0.45 & $\checkmark$ & 15 & 0.44 & 0.59 & $\checkmark$ \\
5 & 0.61 & 0.37 & $\checkmark$ & 16 & 0.75 & 0.50 & $\checkmark$ \\
6 & 0.64 & 0.71 & $\checkmark$ & 17 & 0.82 & 0.36 & Delete \\
7 & 0.61 & 0.51 & $\checkmark$ & 18 & 0.57 & 0.72 & $\checkmark$ \\
8 & 0.65 & 0.58 & $\checkmark$ & 19 & 0.82 & 0.36 & Delete \\
9 & 0.79 & 0.29 & Delete & 20 & 0.47 & 0.52 & $\checkmark$ \\
10 & 0.51 & 0.59 & $\checkmark$ & 21 & 0.64 & 0.71 & $\checkmark$ \\
11 & 0.61 & 0.51 & $\checkmark$ & & & & \\
\hline
\end{tabular}

All the software needed for construction of cloud server in this study was freeware (GPL), the Debian GNU/Linux 5.0.5 (GPL) was adopted for the operation system of server, the application package of Apache2.0, MySQL5.0 and php5 ( Hypertext Preprocessor) was adopted for the web server, the eyeOS1.9 (GPL) was adopted for the cloud operation system and the zohoSuite (GPL) was adopted for the office software. Besides, the functions of zohoSuite are similar to Microsoft office and openoffice.org.

Research instrument: The "Test of Learning Achievement of Spreadsheets Application Software" was designed according to the experiment course in this study and the design procedures were described as follows:

Preparing questions: This study aimed at comparing the differences between the environment of IT education of cloud computing service and the tradition environment of IT education. Although two groups of students were using different tools, they had the same teaching content of lesson. Thus, questions were considered in both teaching environments.

Pretest: The participants of pretest were fifty sixth grade students from Tunglo Elementary School, Miaoli County, Taiwan.
Analysis and selection for question: For the feasibility and appropriateness of the questions, the analyses of difficulty and discrimination were executed after pretest. The difficulty value is between 0 and 1 if the value close to 0 means the question is harder and if the value close to 1 means the question is easier. The discrimination value is between -1.00 and 1.00; negative value means the question has no discrimination and a positive value closer to 1.00 means the question has high discrimination. For a better question the discrimination value should be above 0.3 (Wu, 2009). The standard of selection for the question in this study was difficulty value between 0.4 to 0.8 and the discrimination value above 3.0. Five questions were deleted after the analysis as shown in Table 3. There were 16 questions for the "Test of Learning Achievement for Spreadsheets Application Software".

Reliability analysis: After pretest of learning achievement, the analyses of difficulty and discrimination were conducted to delete unsuitable questions and then the reliability analysis was conducted. The Cronbach á coefficient is 0.805 for reliability analysis and it is in the range of very good according to the judgment of standard in (Wu, 2009). 
Validity analysis: There were five IT experts invited to assess the validity of the question and they are one principal of elementary school, one director of student affairs in elementary school and three chiefs of IT section in elementary school.

Data analysis: First, the pretest and posttest of "Test of Learning Achievement of Spreadsheets Application Software" were arranged for further data analysis. The invalid questionnaires were stricken out and valid questionnaires were numbered and then statistical analysis software SPSS 12.0 (Wu, 2009) was applied to the following statistical analysis.

Descriptive statistics: The descriptive statistics such as mean, standard deviation were used to show the basic statistics.

\section{T test of independent sample:}

- A t test of independent sample was conducted to compare if the basic ability of the students of experiment group and the students of control group is homogeneous according to using the pretest data for the Test of Learning Achievement of Spreadsheets Application Software

- A t test of independent sample was conducted to compare if there exists significant difference between using the environment of IT education of cloud computing in the students of experiment group and the traditional environment of IT education in the students of control group for learning

\section{RESULTS}

The experiment group and control group each had 55 participants take the "Test of Learning Achievement of Spreadsheets Application Software". All 55 samples were valid.

Verification of homogeneity for basic ability: The test of learning achievement for spreadsheets application software was conducted for the experiment group and control group, respectively before the beginning of teaching experiment. A t test of independent sample was conducted to compare if there exists significant difference between experiment group and control group for learning achievement and there was no significant difference between experiment group $(\mathrm{M}=4.10, \mathrm{SD}=$ 1.93 ) and control group $(\mathrm{M}=4.27, \mathrm{SD}=1.67)$ (as shown in Table 4); $\mathrm{t}(108)=-0.475, \mathrm{p}=0.64$ (as shown in Table 5) for the scores. Both results, as shown in Table 4 and Table 5, show that the experiment group and the control group were homogeneous for basic ability.

Verification of significant difference for posttest scores: A t test of independent sample was conducted to compare if there exists significant difference for learning achievement between using the environment of IT education of cloud computing in the students of experiment group and the traditional environment of IT education in the students of control group for learning and there was a significant difference between experiment group $(\mathrm{M}=11.60, \mathrm{SD}=2.73)$ and control group $(\mathrm{M}=9.64, \mathrm{SD}=3.81)$ (as shown in Table 6); $\mathrm{t}$ $(97.839)=3.110, p=0.002$ (as shown in Table7) for the scores. Both results, as shown in Table 6 and Table 7, show that the students of experiment group were better than the students of control group for learning achievement.

Table 4: Pretest statistic of learning achievement

\begin{tabular}{lllll}
\hline Group & $\mathrm{N}$ & Mean & SD & Std. error mean \\
\hline Experiment & 55 & 4.1091 & 1.93096 & 0.26037 \\
Control & 55 & 4.2727 & 1.67171 & 0.22541 \\
\hline
\end{tabular}

Table 5: T test of independent sample of pretest score

\begin{tabular}{|c|c|c|c|c|c|c|c|c|c|}
\hline & \multirow{2}{*}{\multicolumn{2}{|c|}{$\begin{array}{l}\text { Levene's test for } \\
\text { equality of variances }\end{array}$}} & \multicolumn{5}{|c|}{ t-test for equality of means } & \multirow{2}{*}{\multicolumn{2}{|c|}{$\begin{array}{l}\text { Confidence Interval } \\
\text { the of difference }\end{array}$}} \\
\hline & & & & & & & & & \\
\hline & $\mathrm{F}$ & Sig. & $\mathrm{t}$ & df & (2-tailed) & difference & difference & Lower & Upper \\
\hline $\begin{array}{l}\text { Equal varian } \\
\text { assumed }\end{array}$ & 1.84 & 0.177 & -0.475 & 108 & 0.636 & -0.164 & 0.344 & -0.846 & 0.519 \\
\hline $\begin{array}{l}\text { Equal varian } \\
\text { not assumed }\end{array}$ & 9 & & -0.475 & 105.830 & 0.636 & -0.164 & 0.344 & -0.846 & 0.519 \\
\hline
\end{tabular}

Table 6: Posttest Statistic of learning achievement

\begin{tabular}{lllll}
\hline Group & $\mathrm{N}$ & Mean & Std. deviation & Std. error mean \\
\hline Experiment & 55 & 11.60 & 2.726 & 0.368 \\
Control & 55 & 9.64 & 3.807 & 0.513 \\
\hline
\end{tabular}


Am. J. Applied Sci., 8 (9): 864-871, 2011

Table 7: T test of independent sample of posttest score

\begin{tabular}{|c|c|c|c|c|c|c|c|c|c|}
\hline & \multirow{2}{*}{\multicolumn{2}{|c|}{$\begin{array}{l}\text { Levene's test for } \\
\text { equality of variances }\end{array}$}} & \multicolumn{5}{|c|}{ t-test for equality of means } & \multirow{2}{*}{\multicolumn{2}{|c|}{$\begin{array}{l}\text { Confidence } \\
\text { Interval the of } \\
\text { difference }\end{array}$}} \\
\hline & & & $t$ & $\begin{array}{l}\text { Sig } \\
\text { df }\end{array}$ & (2-tailed) & $\begin{array}{l}\text { Mean } \\
\text { difference }\end{array}$ & $\begin{array}{l}\text { Std. error } \\
\text { difference }\end{array}$ & & Unner \\
\hline $\begin{array}{l}\text { Equal varian } \\
\text { assumed }\end{array}$ & 10.171 & 0.002 & 3.110 & 108 & 0.002 & 1.964 & 0.631 & 0.712 & 3.215 \\
\hline $\begin{array}{l}\text { Equal varian } \\
\text { not assumed }\end{array}$ & & & 3.110 & 97.839 & 0.002 & 1.964 & 0.631 & 0.711 & 3.217 \\
\hline
\end{tabular}

\section{DISCUSSION}

According to above analysis results, experiment and control groups were homogeneous in basic ability. Both the posttest statistic and test of independent sample of Posttest score for the learning achievement show that there is significant difference for learning achievement between using the environment of IT education of cloud computing in the students of experiment group and the traditional environment of IT education in the students of control group for learning in the elementary school of experiment.

\section{CONCLUSION}

The environment of IT education based on the infrastructure of cloud computing had been proposed and constructed for students who can login anywhere by using browsers in this study. The experiment results show that there exists significant difference for students' learning achievement of computer in elementary school between after using the environment of IT education of cloud computing service and the traditional environment of IT education for learning. The learning achievement that adopts the environment of IT education of cloud computing service is better than the one that adopts the traditional environment of IT education. Therefore, the environment of IT education of cloud computing which was proposed in this study indeed improves the environment of current IT education to which students could not login after school for learning and resolves no proper space available for students to save their practice files and better learning achievement can be obtained for the environment of IT education of cloud computing service that was proposed in this study.

\section{ACKNOWLEDGMENT}

This study was supported in part by the National Science Council of Taiwan under the Grants NSC 1002511-S-412-001.

\section{REFERENCES}

Belkasmi, M.G., T. Bouchentouf, M. Azizi and A. Benazzi, 2010. Modeling projects in e-learning course: A case of an information technology project. J. Comput. Sci., 6: 823-829. DOI: $10.3844 /$ jcssp.2010.823.829

Gartner, 2010. Gartner Identifies the Top 10 Strategic Technologies. Proceedings of the Analysts Examine Latest Industry Trends During Gartner Symposium/ITxpo, Oct. 18-22, Gartner, Inc. Orlando.

http://www.gartner.com/it/page.jsp?id=1210613

Hsieh, W.F., 2008. Implementation of a Diskless Cluster Computing Environment in a Computer Classroom of Tunghai Campus. Unpublished Master's Thesis. Tunghai University, Taiwan.

Issa, G.F, S.M. Hussain and H. Al-Bahadili, 2009. Economic efficiency analysis for information technology in developing countries. J. Comput. Sci., 5: 751-759. DOI: 10.3844/jcssp.2009.751.759

Mell, P. and T. Grance, 2009. The NIST Definition of Cloud Computing. http://csrc.nist.gov/groups/SNS/cloud-computing/ cloud-def-v15.doc

Omidinia, S., M. Masrom and H. Selamat, 2011. Review of e-learning and ICT infrastructure in developing countries (case study of Iran). Am. J. Econ. Bus. Admin., 3: 120-125. DOI: 10.3844/ajebasp.2011.120.125

Wu, M.L., 2009. SPSS Operation and Application the Practice of Quantitative Analysis of Questionnaire Data. Wun-Nan Book Inc., Taipei, ISBN: 9789571155371, pp: 768.

Yang, C.T., W.F. Hsieh and H.Y. Chen, 2008. Implementation of a diskless cluster computing environment in a computer classroom. Proceedings of the Asia-Pacific Services Computing Conference, Dec. 9-12, IEEE Xplore Press, Yilan, pp: 819-824. DOI: 10.1109/APSCC.2008.266 
Zhong, L., T. Wo, J. Li, B. Li and J. Huai, 2009. vSaaS: A virtual software as a service architecture for cloud computing environment. Beihang University, Beijing, China. http://www.ivic.org.cn/ivic/rawattachment/wiki/WikiStart/ 